\title{
PM Brushless Motor for Aileron/Spoiler system of a Regional Aircraft
}

\author{
Moreno D'Andrea \\ Albanella Research Center \\ UMBRAGROUP S.p.A. \\ Albanella (SA), Italy \\ mdandrea@umbragroup.com \\ Marco Villani \\ Dept. of Ind. and Information Eng. \\ University of L'Aquila \\ L'Aquila, Italy \\ marco.villani@univaq.it
}

\author{
Francesco Fiume \\ Albanella Research Center \\ UMBRAGROUP S.p.A. \\ Albanella (SA), Italy \\ ffiume@umbragroup.com
}

\author{
Davide Macers \\ Albanella Research Center \\ UMBRAGROUP S.p.A. \\ Albanella (SA), Italy \\ dmacera@umbragroup.com
}

\begin{abstract}
The integration of electromechanical actuators in the aircraft systems is one of the major key-point of the aerospace industry, thanks to their advantages, such us minor weight and major efficiency: this trend is called "More-Electric Aircraft".

In this paper, a PM brushless motor has been designed and analyzed to integrate in an electromechanical actuator in a regional aircraft to control aileron/spoiler surface.

As first step, an accurate selection of the active material has been made in order to have the best compromise between envelope and performance. Then, an optimization of the electromagnetic design has been performed in order to maximize the torque-to-current ratio at continuous operation.
\end{abstract}

A surface permanent magnets machine with concentrated windings has been chosen and the proposed motor has the magnets directly glued on the surface of the steel nut. Moreover, in order to improve the power density, the high-performance $\mathrm{CoFe}$ electrical steel has been selected.

Accurate Finite Element analysis and thermal verification have been carried out to ensure that the sized motor could cover the overall range of required performance avoiding overtemperature during the operation.

Keywords-PM Motor, More Electric Aircraft, aileron, Finite Element analysis, optimization, thermal analysis, Cobalt-Iron alloy.

\section{INTRODUCTION}

In the 1990 , one billion people travelled by year, after thirty years this number is four times greater; moreover, people and government have an always bigger sensibility about environmental impact.

The constant passenger increases and the demands of energy saving and air pollution limitation were leading to a new generation of aircraft system that point out the substitution the actual system with an equivalent electric system. This concept is called More Electric Aircraft (MEA).

Actually, the aviation sector is moving to two different directions: engine;

elimination of bleed-air systems and hydraulic

- substitution of hydraulic actuators with electromechanical actuators.
About the second point, there are many reasons that lead to prefer Electromechanical Actuators (EMAs), instead of the hydraulic actuators:

- weight, bulk and maintenance reduction;

- elimination of hydraulic elements (increase of reliability and decrease of vibration);

- increase of performance in terms of decrease of number of component and fewer hydraulic elements.

Aircraft flight control system is composed of a large number of components, each one associated to one or more actuators. In particular, a subdivision is possible (Fig. 1), considering "primary flight control", such as ailerons to manage the aircraft roll and rudders to manage its yaw, and "secondary flight control", such as flaps and slats, that haven't influence on roll, pitch and yaw but are useful to enhance the flight control performance.

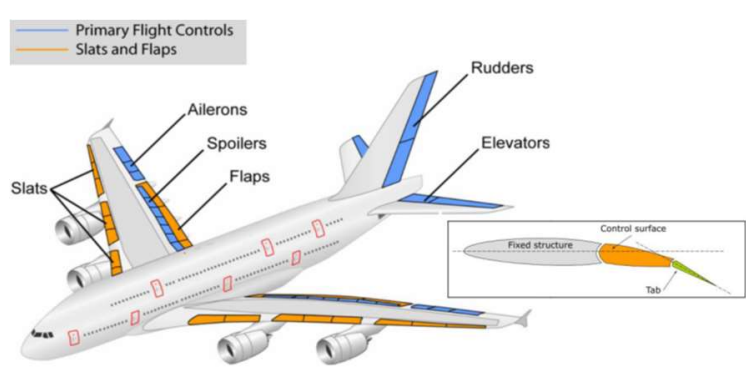

Fig. 1 - Aircraft flight control system

Today the conventional actuators have reached a suitable reliability rate for the severe aerospace standard, so incoming EMAs have not only be designed with high efficiency and density requirements, but need to guarantee similar or higher reliability constraints than traditional hydraulic and pneumatic counterparts, possibly with reduced maintenance costs and with very high dynamics performance.

Different solutions of EMAs are being explored in literature. Reference [1] and [2] present a comparison of electric motors and the key characteristics for aerospace applications. The design of multi-phase Permanent Magnet (PM) motors for aircraft were proposed in [3], [4] and [5]. An interesting application of Switched-Reluctance motor was also reported in paper [6] and [7]. A high-power density 
brushless PM motor for helicopter tail rotor was presented in [8] and [9].

The strong demand of high-performance electric motors for aeronautic applications requires the use of innovative and efficient design procedures, by specific tools and optimization processes, and an accurate choice of the materials, in order to fully satisfy the hard specifications and constraints in terms of encumbrance, weight, reliability and cost.

For this application (aileron and spoiler) a three-phase PM synchronous motor with concentrated winding has been proposed and designed using a sizing procedure and an optimization algorithm linked to a Finite Element (FE) tool. The main goal was to maximize the torque-to-current ratio at continuos duty in compliance with the hard-imposed specifications in terms of performance and encumbrance. Moreover, an accurate thermal analysis has been carried out in order to verify the motor temperature with reference to a typical aircraft duty-cycle.

\section{MOTOR REQUIREMENTS AND MATERIALS}

\section{A. Requirements}

In order to ensure a proper behavior of the primary flight control surface for a regional aircraft, the electric motor has to satisfy the operating points shown in Fig. 2. Moreover, the speed at no load condition has to be higher than $910 \mathrm{rpm}$.

The electric motor is supplied by a $270 \mathrm{~V}$ Bus DC voltage and the input power limitations is $600 \mathrm{~W}$ in Continuous Operation (CO) and $2500 \mathrm{~W}$ in Discontinuous Operation (DO).

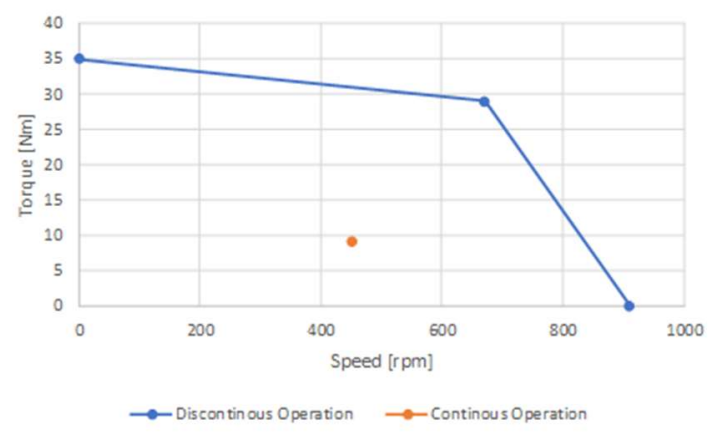

Fig. 2 - Electric Motor Requirements

\section{B. Materials}

High performance motor requires a right choice of the electrical steel that is an important step during the sizing procedure. Moreover, in the aeronautic applications the motor is expected to have a compact design and light weight compared to the motors for other applications and then the electrical steel sheet is required to have higher magnetic flux density under given field strength, namely higher magnetic permeability.

The SiFe sheets are currently the most used material in the realization of electric motors, because they offer a relatively low cost and excellent magnetic properties (low loss, high permeability, high saturation induction, low coercive field). In addition, this material has a good punchability and relatively high thickness $(0.50$ and $0.65 \mathrm{~mm})$. In high - frequency applications to limit the power losses, $\mathrm{SiFe}$ sheets with a reduced thickness $(0.2 \mathrm{~mm}$ and $0.3 \mathrm{~mm})$ are used.
In the last years high permeability materials have been developed, which at same silicon content have higher magnetic induction respect conventional materials [10].

For high power density motors, cobalt iron $(\mathrm{CoFe})$ is generally the most expensive alloy. If alloyed with iron, cobalt reaches the highest maximum saturation magnetization of all materials. With the large maximum flux density, the size and weight of electrical machine cores can be decreased significantly. This allows the design of electrical machines with very high power densities. By varying the ratio between the cobalt and iron content in the material, lower iron losses or a higher mechanical strength can be achieved.

For the proposed design, the high-performance CoFe electrical steel ( $0.35 \mathrm{~mm}$ thickness) has been selected, in order to improve the power density.

\section{PM MOTOR DESIGN AND FE ANALYSIS}

\section{A. Motor design}

A surface PM machine with concentrated windings has been designed; the goal was to define a direct drive PMSM focusing on the key points of performance and reliability.

For this specific application, the 24 stator slots and 20 rotor poles single layer fractional slot motor topology has been selected exhibiting high winding factor. It is easier to manufacture since there is 1 coil slide per slot and provides higher self-inductance and lower mutual inductance hence better fault-tolerance and flux-weakening capability. Moreover, motor with double layer winding may suffer from lower overload torque capability respect to single layer solution due to higher magnetic saturation of the stator tooth tip in the double layer winding machine [11], [12].

The main motor dimensions has been calculated (with reference to the continuous operation $\mathrm{CO}$ ) by the sizing procedure proposed in [13] and [14] that has been carried out by means of a spreadsheet software and FE tool [15]; then, the preliminary design has been refined by an optimization procedure.

The gol was to increase the motor efficiency and then the chosen objective function to maximize has been the torque-tocurrent ratio at $\mathrm{CO}$. Since the stack length and outer stator diameter are imposed, the design variables concerned the stator slot dimensions, the PM size and the stator winding.

The general structure of the optimization problem is the following:

$$
\begin{gathered}
\min f(x) \\
\text { s.t. } g(x) \leq 0 \\
l \leq \mathrm{x} \leq \mathrm{u} \\
\mathrm{x}_{\mathrm{i}} \in \mathrm{Z}, \quad \mathrm{i} \in \mathrm{I}_{\mathrm{Z}}
\end{gathered}
$$

where $f$ is the objective function and $g$ the constraint functions. $\mathrm{Z}$ is the set of the integer numbers, $x \in R^{n}, f: R^{n}$ $\rightarrow R, \mathrm{~g}: R^{n} \rightarrow R^{m}, \quad l, \mathrm{u} \in R^{n}, \mathrm{l}_{\mathrm{i}}, \mathrm{u}_{\mathrm{i}} \in \mathrm{Z}, \mathrm{i} \in \mathrm{I}_{\mathrm{z}}$ The set is called feasible set.

$$
F=\left\{\mathrm{x} \in R^{n}: \mathrm{g}(\mathrm{x}) \leq 0, \quad 1 \leq \mathrm{x} \leq \mathrm{u}\right\}
$$

The set of parameters $\mathrm{x}$ used in the optimization procedure are listed in TABLE I, with their limits. The design optimization needs to satisfy several constraints to guarantee 
the reliability and feasibility of the final design (TABLE I). The slot fill factor has been chosen in order to simplify the winding insertion and this represents a very hard constraint.

In order to efficiently solve the optimization problem of the PM motor, a new algorithm belonging to the class of Controlled Random Search (CRS) algorithms has been used and combined with the FE software. This algorithm described in [16] has been proven to be useful and effective in solving several global optimization problems deriving from real world applications. Similarly to other global optimization methods, CRS algorithms follow a strategy which combines a global search phase and a local search phase. The global search is used to locate the sub-regions "more promising" to contain a global minimizer; the local search is used for determining the global minimizer as soon as a "sufficiently small" neighborhood of this point has been located.

This method follows an approach which can be considered a compromise between a pure random search strategy and a clustering strategy derived by a deterministic local search.

TABLE 1 - Design variable and constraints

\begin{tabular}{|lc|c|c|}
\hline \multicolumn{1}{|c|}{ Variables } & Lower & Upper \\
\hline x1. Inner stator diameter & $\mathrm{mm}$ & 72 & 76 \\
\hline x2. Stator tooth width & $\mathrm{mm}$ & 3.0 & 4.0 \\
\hline x3. Stator slot high & $\mathrm{mm}$ & 13 & 15 \\
\hline x4. PM thickness & $\mathrm{mm}$ & 4.0 & 5.5 \\
\hline x5. Ratio of PM width to pole pitch & 0.75 & 0.85 \\
\hline x6. Number of wires per slot & 50 & 70 \\
\hline x7. Wire size & $\mathrm{mm}^{2}$ & 0.60 & 0.90 \\
\hline \multicolumn{1}{|c|}{ Constraints } & & Limits \\
\hline g1. Slot fill factor & $\mathrm{T}$ & \multicolumn{2}{c|}{$\leq 1.80$} \\
\hline g2. Max flux density in the st. tooth & $\mathrm{T}$ & \multicolumn{2}{c|}{} \\
\hline g3. Max flux density in the st. yoke & $\mathrm{T}$ \\
\hline
\end{tabular}

The Finite Element analysis allows to evaluate the motor performance and the optimization procedure uses the information obtained by the FE program to iteratively update the set of motor parameters and try to identify an "optimal" motor by making a trade-off between the different parameters of the machine.

The final design has been further refined in order to meet the following requirements:

- $\quad$ sinusoidal BEMF;

- low cogging torque and torque ripple.

These constraints have been satisfied by choosing a "variable airgap" that has required an accurate design of the PM profile. The cross section of the final design and winding distribution are shown in Fig. 3: the PM is the high performance $\mathrm{NdFeB} 45 \mathrm{SH}$.

Due to mechanical considerations and the encumbrance limits, the proposed motor has the PMs directly glued on the surface of the steel nut that represents the "rotor" (Fig.3). This choice differs from typical solutions where the rotor core is manufactured with non-oriented lamination material and has the advantage to simply the manufacturing process and the actuator assembling.

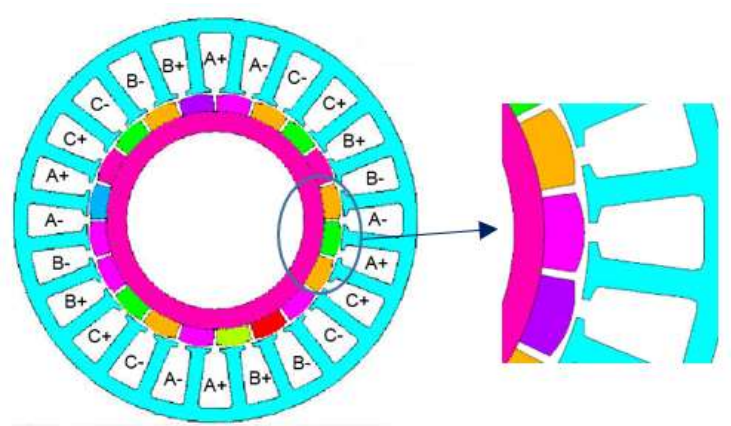

Fig. 3 - Cross section of the PM motor and detail of rotor core

\section{B. FE Analysis and Results}

The motor performance at different operating points, calculated by the FE analysis, are presented in TABLE 2, it includes some of the key dimensions of the optimized design. The temperature of $100^{\circ} \mathrm{C}$ has been imposed for the stator winding and $70^{\circ} \mathrm{C}$ for the magnets.

TABLE 2-Optimized design 20 poles - 24 slots

\begin{tabular}{|c|c|c|c|}
\hline & Design data & Unit & Value \\
\hline \multicolumn{2}{|c|}{ Outer stator diameter } & $\mathrm{mm}$ & 110 \\
\hline \multicolumn{2}{|c|}{ Inner stator diameter } & $\mathrm{mm}$ & 75 \\
\hline \multicolumn{2}{|c|}{ Inner rotor diameter } & $\mathrm{mm}$ & 55 \\
\hline \multicolumn{2}{|c|}{ Stack length } & $\mathrm{mm}$ & 100 \\
\hline \multicolumn{2}{|c|}{ Stator winding } & & Alternate-teeth \\
\hline \multicolumn{2}{|c|}{ N.turns per phase } & & 256 \\
\hline \multicolumn{2}{|c|}{ Wire size } & $\mathrm{mm}^{2}$ & 0.73 \\
\hline \multicolumn{2}{|c|}{ Permanent magnet } & & $\mathrm{NdFeB}-45 \mathrm{SH}$ \\
\hline \multicolumn{2}{|c|}{ Electrical steel } & & $\mathrm{CoFe}-0.35 \mathrm{~mm}$ \\
\hline \multicolumn{2}{|r|}{ Performance } & Unit & Value \\
\hline \multirow{4}{*}{ DO } & Average Torque & $\mathrm{Nm}$ & 29.0 \\
\hline & Speed & $\mathrm{rpm}$ & 670 \\
\hline & Phase Current & Arms & 13.5 \\
\hline & Joule losses & W & 877 \\
\hline \multirow{4}{*}{$\mathrm{CO}$} & Average Torque & $\mathrm{Nm}$ & 9.0 \\
\hline & Speed & $\mathrm{rpm}$ & 450 \\
\hline & Phase Current & Arms & 3.8 \\
\hline & Joule losses & W & 70 \\
\hline
\end{tabular}

Fig. 4 and Fig. 5 show the comparison of the cogging torques with constant and variable airgap and the torque ripple at discontinuous and continuous operation.

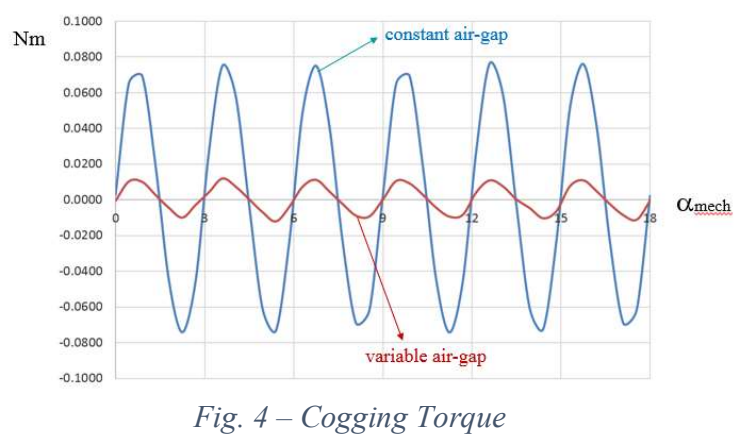




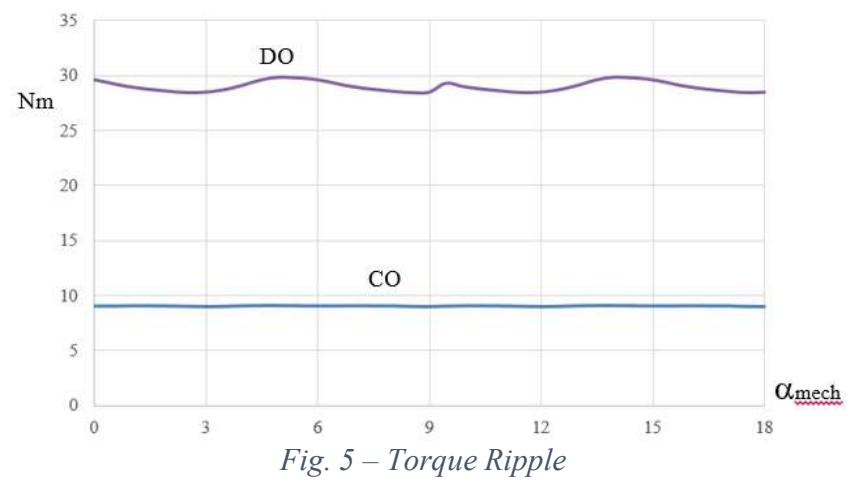

\section{THERMAL ANALYSIS}

\section{A. Scope and Input Data}

Electromagnetic design is the focal point in the sizing of electric motor, but a thermal analysis is necessary to verify the motor temperatures during its operation.

Insulation average life is strongly affected by temperature and overshooting the maximum allowable temperature could led to motor issues, such as short-circuit. Moreover, the temperature raising decreases the torque capability of the motor due to magnet characteristics.

From cooling point of view, the proposed solution does not present a cooling system and the exchange of heat is concentrated in the electric motor interfaces, in particular by natural convection on its stator external surface

To ensure that the proposed design had a proper thermal behavior, a lumped circuit thermal model has been defined and calibrated respect the motor characteristics.

Comparing this method with FEA method, it offers a suitable accuracy avoiding the high computational time typical of FEA analysis.

The input data for the thermal analysis concerned the working cycle of the application and the relative motor losses in different operating points.

The duty cycle has been based on typical aircraft operation. For this specific application, the operation is characterized by five steps and in each one a profile of torque and speed is repeated for a specified time.

Dynamic evaluation of duty cycle has been out of the purpose of the application at this design level, but the operation has to be verified from thermal point of view.

In order to have a smart evaluation of the motor temperature, RMS torque and RMS speed for each profile is calculated and analyzed by electromagnetic FE analysis to evaluate motor power losses, which have been the input data of the thermal analysis (TABLE 3 and Fig. 6). The use of RMS speed and torque instead of the real duty cycle is allowed thanks to the energy content of RMS speed and torque, that is the same of its duty cycle.
TABLE 3 - Thermal analysis input data

\begin{tabular}{|c|c|c|c|c|c|c|}
\hline Step & Time & Torque & Speed & $\begin{array}{c}\text { Joule } \\
\text { Losses }\end{array}$ & $\begin{array}{c}\text { Stator Core } \\
\text { Losses }\end{array}$ & $\begin{array}{c}\text { Magnet } \\
\text { Losses }\end{array}$ \\
\hline & $\mathrm{s}$ & $\mathrm{Nm}$ & $\mathrm{rpm}$ & $\mathrm{W}$ & $\mathrm{W}$ & $\mathrm{W}$ \\
\hline 1 & 6629 & 8.90 & 80.5 & 47.7 & 1.0 & 0.5 \\
\hline 2 & 884 & 8.91 & 161 & 47.8 & 2.4 & 1.0 \\
\hline 3 & 1370 & 10.34 & 322 & 65.9 & 6.8 & 4.9 \\
\hline 4 & 1370 & 13.87 & 402 & 123 & 7.1 & 9.1 \\
\hline 5 & 548 & 20.80 & 402 & 311 & 8.1 & 20.2 \\
\hline
\end{tabular}

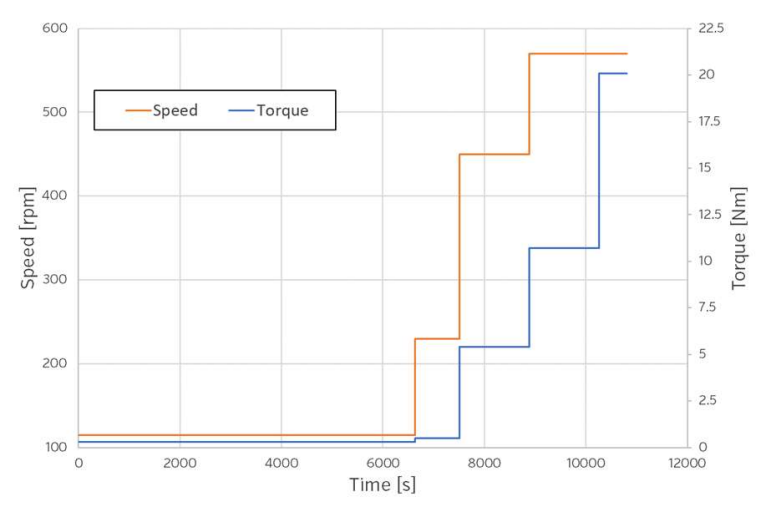

Fig. 6-Duty cycle torque and speed

The ambient temperature has been set to $-10{ }^{\circ} \mathrm{C}$, that is the temperature of external load (flight control actuators are strongly influenced by temperature, due to friction and efficiency variation with temperature).

Then, the motor losses have been applied in the heat sources of electric machine (winding, stator core, etc.) and the results of the thermal analysis are shown in Fig. 7 and TABLE 4. The PM motor shows a reasonable behavior when the duty cycle is applied and the reached temperature are always less than the maximum admissible temperature for the class $\mathrm{H}$ $\left(180^{\circ} \mathrm{C}\right)$.

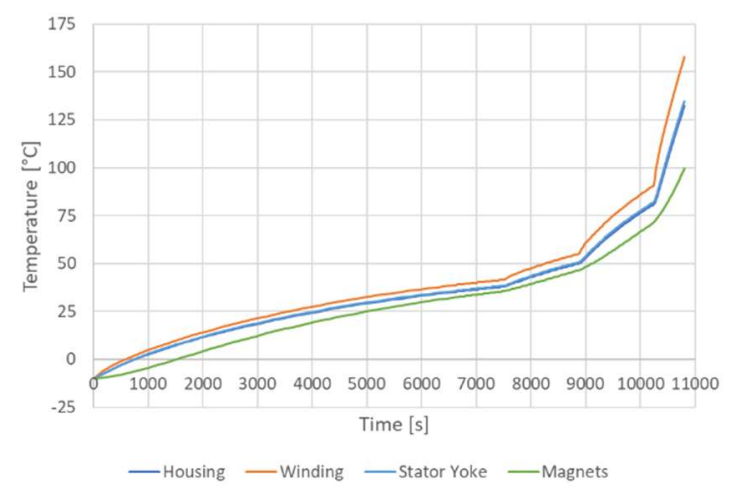

Fig. 7 -Motor temperature vs time

TABLE 4-Maximum temperature

\begin{tabular}{|c|c|}
\hline & Max Temperature \\
\hline & ${ }^{\circ} \mathrm{C}$ \\
\hline Winding & 158 \\
\hline Housing & 130 \\
\hline Magnets & 106 \\
\hline
\end{tabular}




\section{CONCLUSION}

The strong demand of high-performance electric motors for "More-Electric Aircraft" requires the use of innovative and efficient design procedures, by specific tools and optimization processes, in order to fully satisfy the hard specifications and constraints in terms of encumbrance, weight, reliability and cost.

In this paper, a surface PM machine with concentrated windings for primary flight surface has been designed, and the thermal verification has been performed, where the duty cycle has been derived from typical operation of flight control.

The constraints on the encumbrance and performance has required the selection of not standard materials for the stator core and permanent magnets. Moreover, the proposed motor has the PMs directly glued on the surface of the steel nut that represents the "rotor"; this choice allows to reduce the envelope and simplify the motor manufacturing.

The final results show that the proposed solution is able to perform the operation required at aircraft level with proper performance in terms of torque and speed and avoiding possible thermal issue.

The next steps will concern the prototype manufacturing and test-based verification of the electromagnetic and thermal behavior to have a confirmation of electric motor performance.

\section{ACKNOWLEDGMENT}

This project has received funding from the Clean Sky 2 Joint Undertaking under the European Union's Horizonn 2020 research and innovation programme under grant agreement No 755615
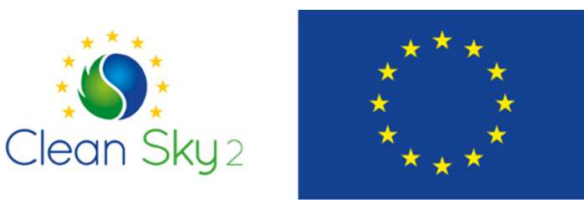

\section{REFERENCES}

[1] E. D. Ganev, "High-Performance Electric Drives for Aerospace More Electric Architectures", 2007 IEEE Power Engineering Society General Meeting, Tampa, USA.
[2] R. T. Naayag, "A Review of More Electric Aircraft Technology", 2013 International Conference on Energy Efficient Technologies for Sustainability, Nagercoil, India.

[3] R.Bojoi, A.Cavagnino, A.Tenconi, S.Vaschetto, "Multiphase PM machine for More Electric Aircraft applications: Prototype for design validation", IECON 2012 - 38th Annual Conference on IEEE Industrial Electronics Society.

[4] E.Chiricozzi, M.Villani, "Analysis of fault-tolerant five-phase IPM synchronous motor", IEEE-ISIE'08. Cambridge, p. 759-763, ISBN: 978-1-4244-1666-0, Cambridge, June 30 2008-July 22008.

[5] M.Villani, M.Tursini, G.Fabri, L.Castellini, "Fault-tolerant PM brushless DC drive for aerospace application”, ICEM 2010, XIX International Conference on Electrical Machines, p. 1-7, ISBN: 978-14244-4174-7, Roma, September 2010.

[6] M.Villani, M.Tursini, G.Fabri, L.Di Leonardo, "A switched-reluctance motor for aerospace application", ICEM 2014, XXI International Conference on Electrical Machines, p. 2073-2079, IEEE, ISBN: 9781-4799-4775-1, Berlin, September 2-5, 2014.

[7] M.Tursini, M,Villani, G.Fabri, L.Di Leonardo, "A switched-reluctance motor for aerospace application: design and analysis and results", Electric Power System Research 142, pp.74-83, Elsevier, 2017.

[8] M.Villani, F.Parasiliti, M.Tursini, G.Fabri, L.Castellini, "PM Brushless motor design for helicopter tail rotor", ICEM 2016, XXII International Conference on Electrical Machines, pp.2669-2675, Losanna, September 2016.

[9] G.Fabri, F.Parasiliti, M.Tursini, M.Villani, L.Castellini, "PM brushless motor for helicopters electric tail rotor drive system", IEEE Internationa Electric Machines and Drives Conference (IEMDC), pp. 1-7, Miami, 21-24 maggio, 2017.

[10] A. Krings, M. Cossale, A. Tenconi, J. Soulard, A. Cavagnino, A. Boglietti, "Magnetic Materials Used in Electrical Machines", IEEE Industry Applications Magazine, Nov/Dec 2017.

[11] A. M. EL-Refaie, "Fractional-slot concentrated-windings synchronous permanent magnet machines: opportunities and challenges", IEEE Trans. on Industrial Electronics, vol. 57, n. 1, January 2010.

[12] D. Ishak, Z.Q.Zhu, D.Howe, "Comparison of PM brushless motors, having either all teeth or alternate teeth wound", IEEE Trans. on Energy Conversion, vol. 21, n. 1, March 2006.

[13] J. F. Gieras and M. Wing, Permanent Magnet Motor Technology, New York, Marcel Dekker Inc., 2002.

[14] J.R. Hendershot and T.J. E. Miller, Design of Brushless PermanentMagnet machines, Motor Design Books LLC, 2010.

[15] L.Di Leonardo, F.Parasiliti Collazzo, M.Tursini, M.Villani, "Transient analysis of PM synchronous motor drives by finite element model cosimulation", IECON 2013 - 39th Annual Conference on IEEE Industrial Electronics Society, p. 6832-6838, ISBN: 978-1-4799-02231, Vienna, Austria, November 10-13, 2013.

[16] F.Parasiliti, M. Villani, S. Lucidi, F. Rinaldi, "Finite Element Based Multi-Objective Design Optimization Procedure of Interior Permanent Magnet Synchronous Motors for Wide Constant-Power Region Operation”. IEEE Trans. on Industrial Electronics, vol. 59, n. 6, June 2012. 